\title{
AVALIAÇÃO FENOTÍPICA E MOLECULAR DA SUSCEPTIBILIDADE À FÁRMACOS EM ISOLADOS CLÍNICOS DE Leishmania spp. OBTIDOS EM UMA ÁREA ENDÊMICA DE LEISHMANIOSES: UMA REVISÃO
}

\author{
THE PHENOTYPIC AND MOLECULAR ASSESSMENT OF DRUG SUSCEPTIBILITY \\ IN CLINICAL ISOLATES OF Leishmania spp. OBTAINED IN AN ENDEMIC AREA FOR \\ LEISHMANIASIS: A REVIEW
}

\section{Joselma Damiana Crovea Pinheiro ${ }^{1}$ Islane Cristina Martins ${ }^{2}$}

RESUMO: Introdução: A Leishmaniose é uma das sete doenças tropicais negligenciadas que mais assolam à população. No ano de 2019, por exemplo, houve o aumento no número de casos desta doença no Brasil, registrando a maior taxa de letalidade na última década, emergindo como um grande problema de saúde pública. Objetivo: $O$ objetivo deste trabalho foi realizar uma revisão integrativa da literatura a fim de discutir a avaliação fenotípica e molecular da susceptibilidade à fármacos em isolados clínicos de leishmaniose. Material e Métodos: Foi feita uma busca das referências nas bases Periódicos CAPES, Pubmed e Google Acadêmico em março de 202I. A investigação permitiu identificar ıo artigos que se adequaram aos critérios estabelecidos. Resultados: Observou-se que 80\% dos artigos comprovaram que os compostos naturais a base de plantas associados com outros fármacos são alternativas fitoterápicas para as espécies de leishmanioses e os demais artigos mencionaram que os medicamentos Glucantime ${ }^{\circledR}$, a Anfotericina B e a Miltefosina são os mais utilizados nos últimos anos, entretanto, causam efeitos adversos. Conclusão: Portanto, foi possível concluir que a avaliação fenotípica e molecular da susceptibilidade à fármacos em isolados clínicos de Leishmania spp. demonstrou que os produtos naturais juntamente com os fármacos Glucantime ${ }^{\circledR}$ e Miltefosina foram mais susceptíveis aos isolados de leishmanioses, pois a maioria dos parasitas morreram após testes laboratoriais in vitro e in vivo acompanhado de agentes químicos, físicos e biológicos.

Palavras-chave: Doenças Endêmicas. Anti-Infecciosos. Leishmania.

ABSTRACT: Introduction: The leishmaniasis is one of the seven neglected tropical diseases that most devastate the population. In 2019, for example, there was a raise in the

1 Graduada em Licenciatura em Ciências Naturais - Biologia pela Universidade Federal do Maranhão UFMA. Especialista em Metodologia de Ensino de Biologia e Química pela Faculdade Venda Nova do Imigrante-FAVENI. E-mail: joselmaoo.jp@gmail.com. ORCID: https://orcid.org/oooo-ooor-8834-6i26. 2 Doutora em Neurociências. Programa de Pós-graduação UFPE. ORCID: https://orcid.org/oooo-0003-23512730 
number of cases of this disease in brazil, recording the highest fatality rate in the last decade, emerging as a major public health problem. Objective: The purpose of this work was to carry out an integrative literature review for discussing the phenotypic and molecular assessment of drug susceptibility in clinical isolates of leishmaniasis. Material and methods: It was carried out a search of the references in the capes, pubmed and academic google journals in march 202r. The investigation allowed the identification of ro papers that met the established criteria. Results: it was noted that $80 \%$ of the papers proved that natural herbal compounds associated with other drugs are herbal alternatives for leishmaniasis species and the other papers mentioned that the drugs glucantime ${ }^{\circledR}$, amphotericin $b$ and miltefosine are the most used in recent years, however, they cause adverse effects. Conclusion: Thus, it was possible to conclude that the phenotypic and molecular evaluation of drug susceptibility in clinical isolates of Leishmania spp. showed that natural products along with the drugs glucantime ${ }^{\circledR}$ and miltefosina were more susceptible to leishmaniasis isolates, as most of the parasites died after laboratory tests in vitro and in vivo accompanied by chemical, physical and biological agents.

Keywords: Endemic Diseases. Anti-Infectious. Leishmania.

\section{INTRODUÇÃO}

A Leishmaniose é uma doença parasitária causada pelo protozoário flagelado do

gênero Leishmania spp. da família Trypanosomatidae, são divididas cerca de 20 espécies de Leishmania patogênica em humanos, entre as mais comuns são, a visceral ou calazar (LV) e L. tegumentar ou cutânea (LT) (CONRADO; BARROS, 2019).

No entanto existem outras formas mais raras como, a mucocutânea, difusa e dérmica. As principais espécies encontradas no país são L. amazonensis, L. braziliensis, e L. guyanensis, estas, são apontadas como causadora da leishmaniose tegumentar e a L. infantum causa a Leishmania visceral canina (LVC) (ARAUJO; CONRADO 2019).

Além disso, é uma doença endêmica no mundo inteiro, é encontrada em 98 países entre eles o Brasil, e acomete principalmente os países em desenvolvimento, as populações pobres, a pessoa com o estado imunológico debilitado, a desnutrição e o deslocamento geográfico (LIMA, 2020; BARROS, 2019).

Nesse sentido, os fármacos utilizados no tratamento dessa doença, ainda são ineficientes, causam efeitos colaterais, toxicidade, pancreatite, hepatoxicidade, logo são necessários a busca por novos medicamentos mais seguros e eficazes, com baixo custo, para população em geral (BADIRZADEH et al., e LIMA, 2020; CONRADO, 2019). 
Dessa forma, os remédios anti-infecciosos à base de compostos naturais também são importantes, entre eles; agentes antibacterianos, antivirais, antifúngicos, antiparasitários e antileishmanial (CONRADO, 2019).

Por conseguinte, a leishmaniose possui duas formas biológicas, a forma promastigota, que cresce no interior do tubo digestivo do vetor infectado, e a amastigota que vive na parte interna das células fagocíticas do hospedeiro mamífero (PAES, 2017).

Dito isso, a infecção ocorre pela picada das fêmeas de flebotomíneos infectados que contaminam um hospedeiro humano ou animal, estes últimos ingerem amastigotas, que por sua vez, passam por diversas divisões e transformam em promastigotas, reiniciando o ciclo (DOS SANTOS NOGUEIRA et al., 2019).

Não só isso, mas o diagnóstico da LVC tem sido preocupante na saúde pública, devido às altas taxas de cães infectados assintomáticos e variedades de sinais clínicos (LIMA, 2020; DOS SANTOS NOGUEIRA et al., 2019).

E nas últimas décadas, a reação em cadeia da polimerase em tempo real (qPCR), vem sendo muito utilizada, por ser um método que diagnostica animais infectados assintomáticos (DOS SANTOS NOGUEIRA et al., 2019).

Além disso, uma das espécies mais comuns são LT que apresentam em seu quadro clínicos erupções cutâneas, lesões desfigurantes, no entanto a leishmaniose visceral é mais perigosa, devido seu alto índice e se não tratada pode levar o paciente até à morte (BARROS, 2019).

Portanto, não existe nenhuma vacina disponível para amenizar essa doença, sendo que o tratamento é um dos principais métodos para controlá-las (MUENDO; BADIRZADEH et al., 2020).

Mas, o que vem preocupando a população é o tratamento com os antimoniais pentavalentes que a mais de 50 anos estão sendo utilizados como de primeira linha e outros medicamentos como anfotericina $\mathrm{B}$ e Miltefosina (ARAUJO; DOS SANTOS NOGUEIRA et al, 2019). 
Dessa maneira, estudos comprovam que os produtos naturais à base de plantas, e seus derivados são fundamentais no desenvolvimento de novos fármacos para as espécies de leishmanioses (CONRADO; BADIRZADEH et al.,; LIMA, 2020).

Diante disso, dados epidemiológicos do ano (2021) revelam que em 2019, foram confirmados 2.529 casos novos de LV no Brasil e na região Nordeste é registrada o maior número de casos (49,1\%), estando em primeiro lugar o Maranhão (15,42\%). A taxa de letalidade foi $9 \%$, a maior nos últimos dez anos. Já a LT, foram registrados 15.484 casos no país, com maior predominância na região Norte $(42,8 \%)$, o que aponta para a necessidade de novos fármacos para combater a alta incidência (BRASIL, 202I). Logo, estudar os isolados clínicos de leishmaniose e susceptibilidade a fármacos contribuirá para o monitoramento dos aspectos fenotípicos, como a proliferação, viabilidade, infectividade e a susceptibilidade do parasita a fármacos (ARAÚJO, 2019).

Por isso, o objetivo do presente estudo foi realizar uma revisão integrativa da literatura a fim de discutir a avaliação fenotípica e molecular da susceptibilidade a fármacos em isolados clínicos de Leishmania.

\section{MATERIAL E MÉTODOS}

Foi feito um levantamento da literatura em março de 202I, nas bases de dados Periódicos CAPES, Pubmed e Google Acadêmico. Os descritores utilizados foram os seguintes: "Doenças Endêmicas" AND "Anti-Infecciosos” AND 'Leishmania” e, em inglês,"Endemic Diseases" AND 'Anti-Infective Agents" AND 'Leishmania” em todas as bases de dados. Foram selecionados io artigos sendo incluídos segundo os critérios de elegibilidade conforme a Figura I. Os critérios de inclusão foram: artigos nos idiomas inglês, espanhol e português, nos últimos cinco anos, envolvendo avaliação fenotípica e molecular da susceptibilidade à fármacos em isolados clínicos de Leishmania spp. obtidos em uma área endêmica de leishmaniose. Os critérios de exclusão foram artigos de revisão de literatura ou metanálise. 
FIGURA I. FLUXOGRAMA E CRITÉRIOS DE SELEÇÃO E INCLUSÃO DOS ARTIGOS
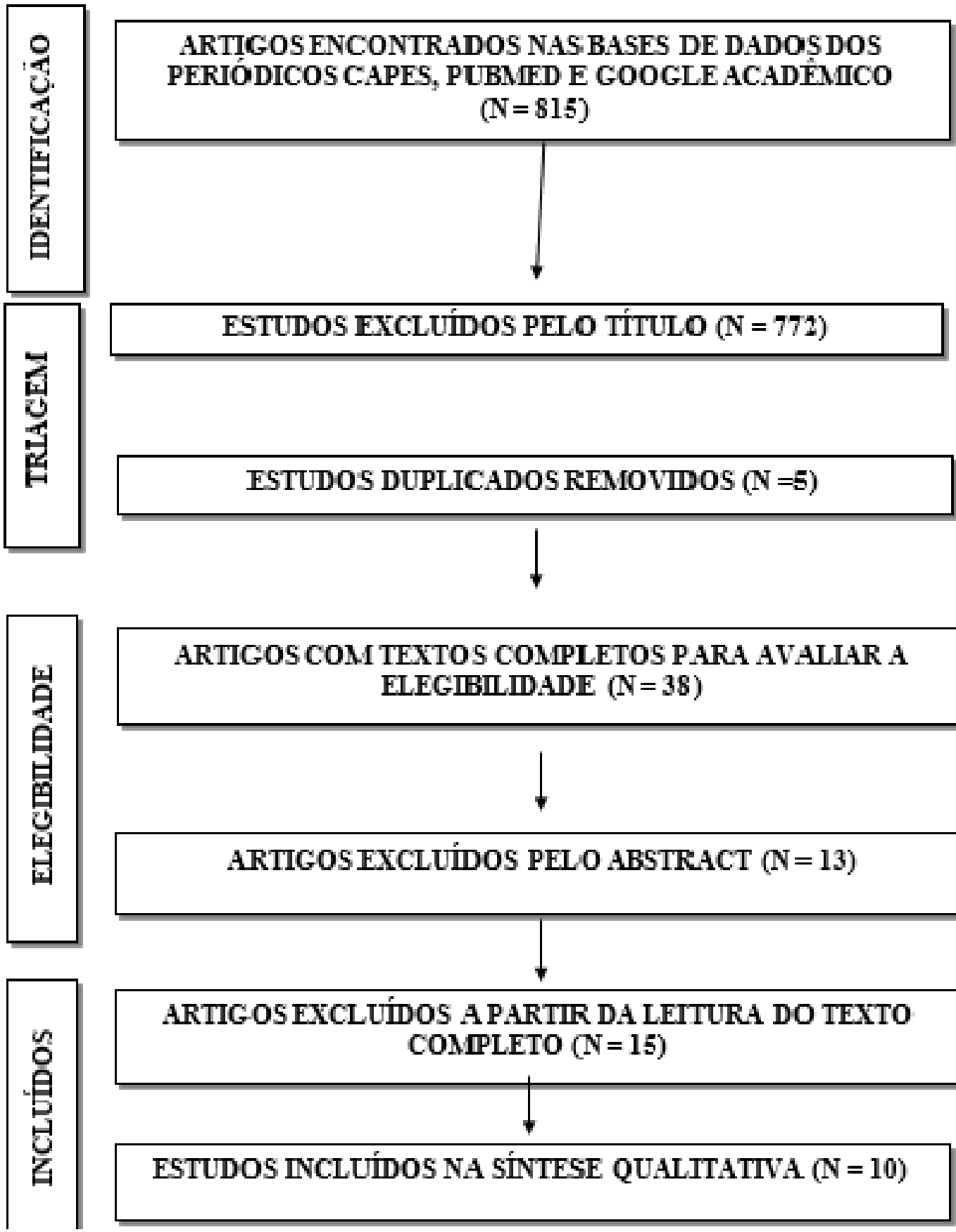

ESTUDOS DUPLICADOS REMOVIDOS ( $\mathbf{N}=\mathbf{5})$
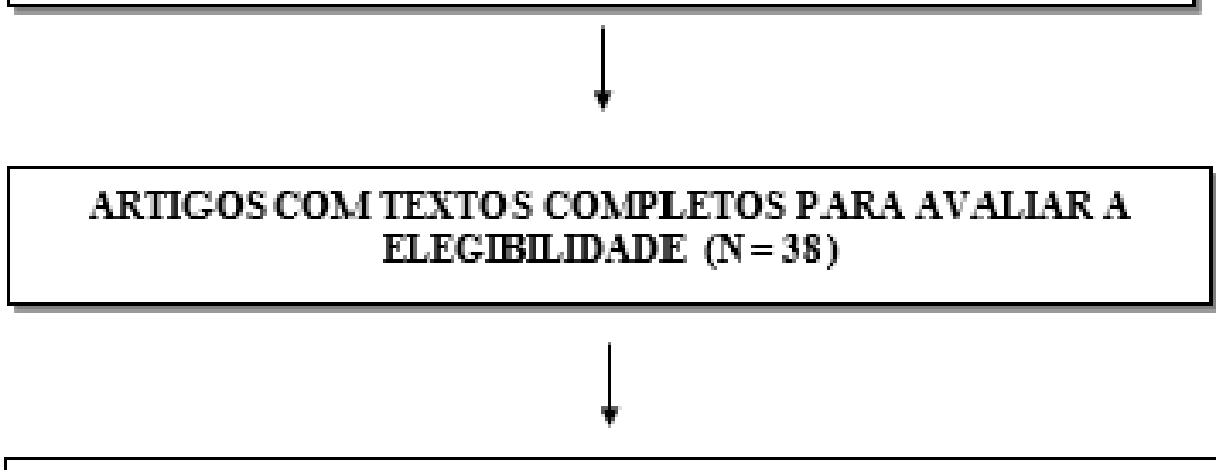

ARTIGOS EXCLÚiDOS PELO ABSTRACT (N=13)

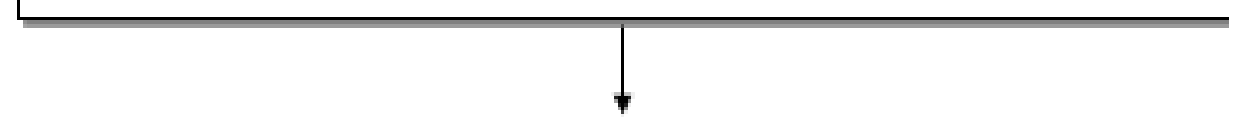

ARTIGOS EXCLUÍDOS A PARTIR DA LEITURA DO TEXTO COMPLETO $(\mathrm{N}=15)$

ESTUDOS INCLUIDOS NA SÍNTESE QUALITATTVA (N = 10)

Fonte: as autoras

\section{RESULTADOS}

Os resultados do presente estudo encontram-se na Tabela I. 
Tabela I - Demonstrativo dos artigos que integram a Revisão Integrativa

\begin{tabular}{|c|c|c|c|c|c|c|}
\hline I & 2021 & $\begin{array}{l}\text { The potential role } \\
\text { and apoptotic } \\
\text { profile of three } \\
\text { medicinal plant } \\
\text { extracts on } \\
\text { leishmania tropica } \\
\text { by mtt assay, } \\
\text { macrophage } \\
\text { model and flow } \\
\text { cytometry } \\
\text { analysis }\end{array}$ & $\begin{array}{l}\text { Mozhde Ilaghi, Iraj } \\
\text { Sharifi, Fariba } \\
\text { Sharififar, } \\
\text { Fatemeh Sharifi, } \\
\text { Razieh Tavakoli } \\
\text { Oliaee, Zahra } \\
\text { Babaei, Manzume } \\
\text { Shamsi } \\
\text { Meimamandi,Alire } \\
\text { za Keyhani, Mehdi } \\
\text { Bamorovat. }\end{array}$ & $\begin{array}{l}\text { Parasite } \\
\text { Epidemiology } \\
\text { and Control }\end{array}$ & $\begin{array}{l}\text { Explorar a atividade } \\
\text { leishmanicida e o perfil } \\
\text { apoptótico de três } \\
\text { extratos de folhas } \\
\text { (de Quercus velutina, } \\
\text { Calotropis } \\
\text { procera e Nicotiana } \\
\text { tabacum) em estágios } \\
\text { de Leishmania trópica. }\end{array}$ & $\begin{array}{l}\text { Todos os extratos vegetais inibiram a } \\
\text { taxa de proliferação de promastigotas e } \\
\text { amastigotas } \\
\text { o,oor); especialmente, } Q \text {. } \\
\text { velutina representou o mais baixo } \\
\text { IC 5o em ambas as fases. Além } \\
\text { disso, Q.velutina apresentou o menor } \\
\text { número de amastigotas em cada } \\
\text { macrófago em comparação com os } \\
\text { outros grupos (4,5 } \mu \mathrm{g} / \mathrm{mL}) \text {. A } \\
\text { porcentagem de apoptose parasitária em } \\
\text { Iooo } \mu \mathrm{g} / \text { mL de } Q \text {. velutina, } C \text {. procera, } N \text {. } \\
\text { tabacum e Glucantime }{ }^{\circledR} \text { foram } 37,4 \text {, I8,6, } \\
\text { 8,5 e 52,4, respectivamente. Amastigotas } \\
\text { (estágio clínico) } \\
\text { significativamente mais suscetíveis aos } \\
\text { 8extratos e também Glucantime }{ }^{\circledR} \text { do que } \\
\text { promastigotas }(P<0,0 o r) \text {. }\end{array}$ \\
\hline
\end{tabular}




\begin{tabular}{|c|c|c|c|c|c|c|}
\hline$\# \mathrm{~N}$ & Data & Título & Autores & Periódico & Objetivos & Resultados \\
\hline
\end{tabular}




\begin{tabular}{|c|c|c|c|c|c|c|}
\hline 3 & 2020 & $\begin{array}{l}\text { Estudo in vitro da } \\
\text { atividade anti- } \\
\text { leishmania de } \\
\text { compostos } \\
\text { sintéticos } \\
\text { derivados espiro- } \\
\text { acridínicos sobre } \\
\text { leishmania } \\
\text { amazonensis. }\end{array}$ & Viviane Silva Lima & $\begin{array}{l}\text { TCC } \\
\text { apresentado } \\
\text { ao programa } \\
\text { de graduação } \\
\text { em farmácia } \\
\text { da UFP }\end{array}$ & $\begin{array}{l}\text { Avaliar a atividade anti- } \\
\text { Leishmania de derivados } \\
\text { espiro-acridínicos e do } \\
\text { fármaco de referência } \\
\text { contra formas } \\
\text { promastigotas de L. } \\
\text { amazonensis e a sua } \\
\text { citotoxicidade frente a } \\
\text { eritrócitos humanos. }\end{array}$ & $\begin{array}{l}\text { Os derivados espiro-acridínicos } \\
\text { (AMTAC io e AMTAC } 13 \text { ) e o fármaco } \\
\text { de referência apresentaram atividade } \\
\text { contra promastigotas de L. amazonensis, } \\
\text { com CI5o de 2,91 } \pm \mathrm{I}, 664 \mu \mathrm{g} / \mathrm{mL}, 6,37 \pm \\
2,035 \mu \mathrm{g} / \mathrm{mL} \text { e o,82 } \pm \text { o,03882 } \mu \mathrm{g} / \mathrm{mL} \text {, } \\
\text { respectivamente. O fármaco apresentou } \\
\text { maior citotoxicidade frente a eritrócitos } \\
\text { humanos em comparação aos espiro- } \\
\text { acridínicos. Dessa forma, observou-se } \\
\text { que os derivados espiro-acridínicos } \\
\text { possuem atividade anti-leishmania } \\
\text { efetiva contra as formas promastigotas e } \\
\text { não apresentam toxicidade. }\end{array}$ \\
\hline
\end{tabular}




\begin{tabular}{|c|c|c|c|c|c|c|}
\hline$\# \mathrm{~N}$ & Data & Título & Autores & Periódico & Objetivos & Resultados \\
\hline
\end{tabular}

Continua

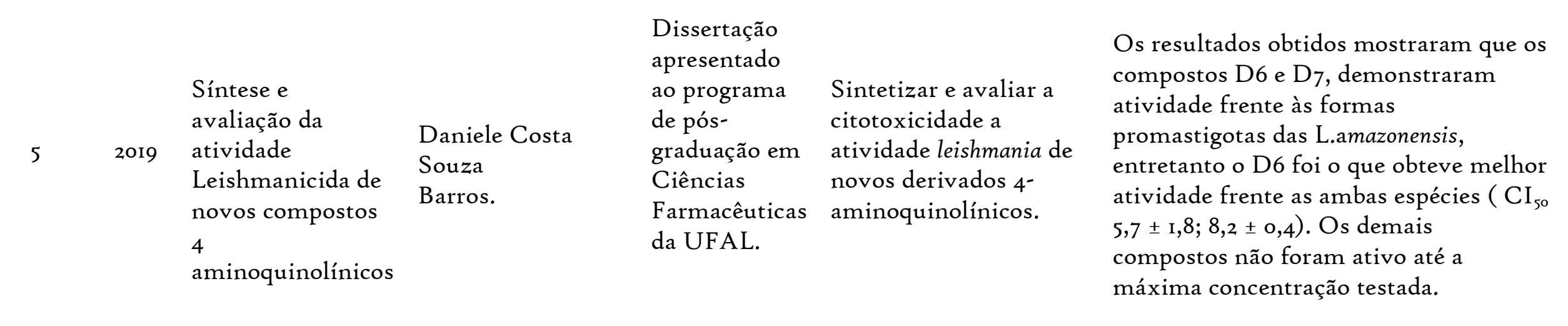




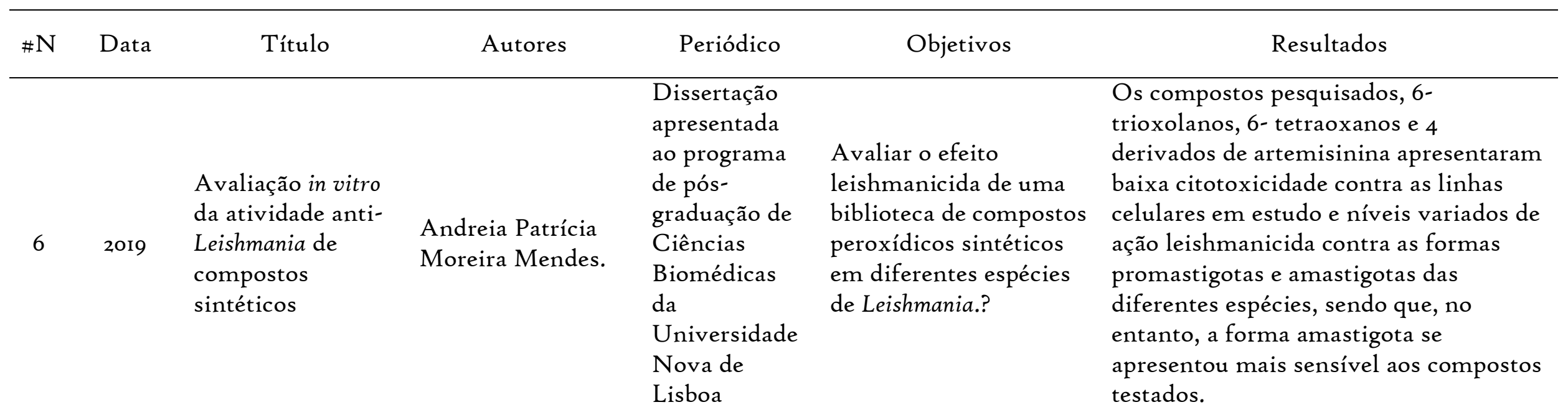




\begin{tabular}{|c|c|c|c|c|c|c|}
\hline$\# \mathrm{~N}$ & Data & Título & Autores & Periódico & Objetivos & Resultados \\
\hline 7 & 2019 & $\begin{array}{l}\text { Prospecção e } \\
\text { identificação de } \\
\text { compostos } \\
\text { isolados de } \\
\text { phyllanthus } \\
\text { amarus schum } \\
\text { and thonn com } \\
\text { potencial } \\
\text { atividade } \\
\text { leishmanicida }\end{array}$ & $\begin{array}{l}\text { Gabrielly Galdino } \\
\text { Conrado. }\end{array}$ & $\begin{array}{l}\text { Tese } \\
\text { apresentado } \\
\text { ao programa } \\
\text { de pós- } \\
\text { graduação de } \\
\text { Ciências da } \\
\text { UEC. }\end{array}$ & $\begin{array}{lr}\text { Avaliar a atividade } \\
\text { leishmanicida } & \text { de } \\
\text { extratos, frações e } \\
\text { compostos } r \text { isolados } \\
\text { contra as formas } \\
\text { promastigotas } & \text { e } \\
\text { amastigotas } & \\
\text { intracelulares } & \text { de } \\
\text { Leishmania amazonenses. }\end{array}$ & $\begin{array}{l}\text { O extrato hexano: acetato de etila de P. } \\
\text { amarus (HEA), rico em lignanas, } \\
\text { apresentou atividade leishmanicida } \\
\text { moderada contra promastigotas de L. } \\
\text { amazonensis com EC5o de } 72,17 \mu \mathrm{g} / \mathrm{mL} \text {. } \\
\text { Houve um aumento significativo desta } \\
\text { atividade conforme o HEA foi sendo } \\
\text { fracionado. As lignanas 5-demetoxi- } \\
\text { nirantina (5), lintetralina (7) e } \\
\text { nirtetralina (9) apresentaram EC50 de } \\
51,86,23,57 \text { e 43,27 } \mu \mathrm{M} \text {, respectivamente. } \\
\text { As lignanas isoladas apresentaram } \\
\text { atividade promissora frente amastigotas } \\
\text { intracelulares, formas clinicamente } \\
\text { relevantes dos parasitas para patogenia } \\
\text { da doença de leishmaniose. }\end{array}$ \\
\hline
\end{tabular}




\begin{tabular}{|c|c|c|c|c|c|c|c|}
\hline 8 & 2019 & $\begin{array}{l}\text { Use of miltefosine } \\
\text { to treat canine } \\
\text { visceral } \\
\text { leishmaniasis } \\
\text { caused by } \\
\text { Leishmania } \\
\text { infantum in Brazil }\end{array}$ & $\begin{array}{l}\text { Fabio dos Santos } \\
\text { Nogueira, Valdir } \\
\text { Carlos Avino, } \\
\text { Fredy Galvis- } \\
\text { Ovallos, Vera } \\
\text { Lucia Pereira- } \\
\text { Chioccola, Marcio } \\
\text { Antonio Batistella } \\
\text { Moreira, Ana } \\
\text { Paula Peres Lopes } \\
\text { Romariz, Letícia } \\
\text { M. Molla e Ingrid } \\
\text { Menz. }\end{array}$ & $\begin{array}{l}\text { Parasites } \\
\text { Vectors }\end{array}$ & $\&$ & $\begin{array}{l}\text { Avaliar a eficácia da } \\
\text { miltefosina observando } \\
\text { uma redução dos sinais } \\
\text { clínicos em cães } \\
\text { infectados e } \\
\text { infectividade ao vetor } \\
\text { por Leishmania infantum. }\end{array}$ & $\begin{array}{l}\text { Foram observados: a remissão dos sinais } \\
\text { clínicos com redução nas pontuações } \\
\text { clínicas para } 94,2 \% \text { dos animais; uma } \\
\text { redução estatisticamente significativa } \\
(98,7 \%) \text { na carga parasitária por qPCR; } \\
\text { e uma redução na infectividade para } \\
\text { flebotomíneos. Após o tratamento, } \\
74,2 \% \text { dos animais permaneceram ou se } \\
\text { tornaram não infecciosos. O estudo } \\
\text { indica que o uso de miltefosina } \\
\text { administrada por via oral por } 4 \text { semanas } \\
\text { contribui para uma melhora clínica e } \\
\text { redução da infectividade de cães para } L \text {. } \\
\text { infantum. }\end{array}$ \\
\hline
\end{tabular}




\begin{tabular}{|c|c|c|c|c|c|c|}
\hline IO & 2017 & $\begin{array}{l}\text { Análise } \\
\text { comparativa de } \\
\text { aspectos } \\
\text { biológicos e } \\
\text { moleculares de } \\
\text { isolados de } \\
\text { Leishmania } \\
\text { infantum }\end{array}$ & $\begin{array}{l}\text { Taiana Ferreira } \\
\text { Paes. }\end{array}$ & $\begin{array}{l}\text { Dissertação } \\
\text { apresentada } \\
\text { ao programa } \\
\text { de pós } \\
\text { graduação de } \\
\text { Biologia } \\
\text { Celular e } \\
\text { Molecular da } \\
\text { FIOCRUZ }\end{array}$ & $\begin{array}{l}\text { Buscar diferenças } \\
\text { biológicas e moleculares } \\
\text { entre L. (i.) infantum } \\
\text { (LII) e L. (i.) chagasi } \\
\text { (LIC), bem como } \\
\text { investigar o papel da } \\
\text { arginase/NOS na } \\
\text { relação parasito- } \\
\text { hospedeiro. }\end{array}$ & $\begin{array}{l}\text { A LII mostrou-se mais infectiva que a } \\
\text { LIC tanto in vivo quanto in vitro. } \\
\text { Observou-se que camundongos BALB/c } \\
\text { foram mais susceptíveis à infecção do } \\
\text { que os Swiss Webster. Nas células do } \\
\text { baço e fígado dos animais infectados por } \\
\text { ambos os parasitos, ocorreu uma } \\
\text { diferença na atividade da NOS e da } \\
\text { ARG. In vitro, promastigotas de LII } \\
\text { isoladas das duas linhagens de } \\
\text { camundongos apresentaram maior } \\
\text { atividade da ARG do que as de LIC, } \\
\text { porém, não se observou diferença na } \\
\text { produção de NO intracelular entre estes } \\
\text { parasitos. As sequências do gene da } \\
\text { ARG foram idênticas entre ambos os } \\
\text { parasitos. Contudo, apesar desta } \\
\text { identidade, as promastigotas } \\
\text { Japresentaram expressão diferente deste } \\
\text { gene. }\end{array}$ \\
\hline
\end{tabular}




\section{DISCUSSÃO}

O objetivo do presente estudo foi realizar uma revisão integrativa de literatura mundialmente sobre avaliação fenotípica e molecular da susceptibilidade à fármacos em isolados clínicos de Leishmania spp, visto que é necessário novos fármacos para reduzir os casos dessa doença (CONRADO, 2019).

Segundo (ILAGHI et al., 202I), três extratos das folhas das plantas Quercus velutina, Calotropis procera e Nicotiana tabacum foram analisadas em diferentes concentrações in vitro e demonstraram serem eficientes contra L. tropica, impedindo a replicação das formas promastigotas e amastigotas.

Não só isso, mas, as amastigotas e Glucantime ${ }^{\circledR}$ foram mais aptos aos produtos vegetais. No entanto, o Glucantime ${ }^{\circledR}$ conduziu mais ação apoptótica do que os extratos metanólicos (ILAGHI et. al., 202I).

Bem como, no artigo de Araújo (2019), confirma-se que o antimoniato de meglumina (Glucantime ${ }^{\circledR}$ ) é um fármaco muito consumido no país, por ser de primeira classe no tratamento da leishmaniose humana.

E, o extrato da folha de Prosopis juliflora, também é forte candidato para redução das formas de amastigotas e promastigotas, pois durante os estudos biológicos de Muendo (2020), 98\% dos parasitas foram mortos, enquanto o estibogluconato de sódio (SSG), exibiu menor efeito sobre as promastigotas.

Além disso, esse fenômeno pode ocorrer devido à eficiência e segurança da planta $(P$. Juliflora), e possibilitou aumento no nível de anticorpos IgG nos camundongos. Desse modo, o extrato do PJ é uma opção para o tratamento da Leishmania donavani (MUENDO, 2020).

Mas também, Conrado (2019), avaliou também testes in vitro da Phyllanthus amarus, uma erva muito utilizada para uso medicinais e etnofarmacológicos, pois, seus princípios ativos conduzem benefícios no combate há vários tipos de doenças, inclusive a Leishmaniose.

Isso se deve ao fato de que, as lignanas presente na $P$. amarus trata tanto as formas promastigotas quanto amastigotas do parasita da L.amazonenesis, além de não ser tóxicos aos mamíferos (CONRADO, 2019). 
Ainda, sobre produtos naturais, Badirzadeh (et.al, 2020), afirmam que o fragmento da Urtica dioica é considerado fitoterápico in vitro e in vivo medicamentoso anti-leishmanial, pois durante os experimentos não houve toxicidade nos hospedeiros e metade das formas do parasita morreram.

Por isso, o uso da planta herbácea é uma alternativa para o tratamento de uma das doenças parasitárias ((BADIRZADEH et al., 2020).

Nesse sentido, Lima (2020) confirma que os derivados espiro-acridínicos (AMTAC Io e AMTAC 13), impedem o desenvolvimento do parasita, podendo ser um forte pretendente terapêutico para doenças endêmicas.

Entretanto, o fármaco de referência Anfotericina B, apresenta citoxicidade nos glóbulos vermelhos humanos, já os derivados espiro-acridínicos não são tóxicos aos mamíferos (LIMA, 2020).

Ainda sobre toxicidade foi também verificado nos estudos realizados por Mendes (2019), onde os compostos peróxidos - 6 trioxolanos, 6 tetraoxanos e 4 derivados de artemisinina foram testados, e observou-se que ocorreu baixa toxicidade em relação às linhas celulares J774. Ar e THP-I.

E, durante esse estudo evidenciaram diversos níveis de ação leishmanicida contra as formas promastigotas e amastigotas, entretanto, as amastigotas mostraram-se mais vulneráveis aos agentes testados (MENDES, 2019).

Não só isso, mas, os novos compostos sintetizados 4- aminoquinolínicos foram testados, contra as formas promastigotas Leishmania amazonensis e chagasi, logo, observou-se que o composto D6 apontou desempenho relevantes frente às duas espécies (BARROS, 2019).

Mas, o composto $\mathrm{D}_{7}$ apresentou melhor atividade sobre a Leishmania chagasi, no entanto, reduziu sua ação contra a L. amazonenses. Já em relação à citoxicidade o Dı e D5 são menos tóxicos (BARROS, 2019).

Nesse sentido, nos estudos de Paes (2017), grupos de camundongos BALB/c e Swiss Webster infectados com L. (i) chagasi (LIC) e L.(i.) infantum (LII) foram testados in vitro e in vivo e confirmou-se que a Leishmania Infantum e Chagasi são bem semelhantes, porém, elas possuem diferenças molecular e biológicas. 
Contudo, a L. infantum ilustrou mais perigosa, com elevado índice de infecção, contribuindo em maiores formas de disseminação do vírus (PAES, 2017).

Dito isso, Paes (2017), ressalta que houve diferenças entre as enzimas Óxido nítrico sintase (NOS) e Arginase durante a infecção in vivo, apontando que estes protozoários podem comprometer as funções vitais da L-arginina do hospedeiro infectado.

Mas também, Dos Santos Nogueira (et. al., 2019), relata que caninos infecciosos com LVC passaram por testes clínicos e laboratoriais. Após esse período, notou-se que o medicamento à base de Miltefosina (Milteforan ${ }^{\circledR}, \mathrm{Virbac}$ ) por via oral no período de um mês facilita a diminuição da infecção de cães com L. infantum.

Além disso, Araújo (2019), ressalta que a miltefosina foi um dos primeiros fármacos utilizados no tratamento da LV na Índia. Já na Colômbia é usado para tratar a leishmaniose cutânea. No entanto, no Brasil é consumida via oral para tratar a LT (Brasil, 202I).

A saber, constata que a carga parasitária foi comprovada usando a qPCR e os animais tratados são menos prejudiciais para os flebotomíneos (DOS SANTOS NOGUEIRA et. al., 2019).

Então, no artigo de Katinas (et al., 2017) as sulfonamidas foram caracterizadas como compostos medicinais utilizados no tratamento das doenças negligenciadas. Logo, elas e seus derivados solúveis em água foram testados in vitro e avaliados, resultando em um composto propício para combater a Leishmaniose.

Portanto, diversos fármacos estão sendo frequentemente testados com isolados clínicos para combater as espécies de leishmaniose no Brasil e no mundo.

\section{CONCLUSÃO}

Esse trabalho tem objetivo de identificar literaturas que abordam sobre a avaliação fenotípica e molecular da susceptibilidade à fármacos em isolados clínicos de Leishmania spp. revisando-as e considerando que a leishmaniose é um grande problema de saúde pública mundialmente.

Diante disso, notou-se que após testes laboratoriais in vitro e in vivo, os produtos naturais como Prosopis juliflora, Phyllanthus amarus dentre outros, citados nos artigos desta revisão, são alternativas fitoterápicas para tratamento das espécies de Leishmania. 
Não só isso, mas, observou-se que os antimoniais Glucantime ${ }^{\circledR}$, a Anfotericina B e a Miltefosina são os medicamentos mais utilizados no tratamento das espécies de leishmanioses juntamente com produtos naturais.

Além disso, identificou-se que a Anfotericina B, um dos fármacos muito consumido no país, ainda causa toxicidade nos seres humanos. Diante disso, é necessário intensificar estudos na busca de novos medicamentos para comprovar sua segurança e eficácia, pois ainda não existe vacina para amenizar essa enfermidade.

Então, nessa revisão, fica evidente que os extratos naturais têm várias funções biológicas e clínicas e são muito utilizados na medicina alternativa, por ser de baixo custo, acessível, menos tóxicos e suas formas são eficazes no tratamento de diversas infecções parasitárias, inclusive a Leishmaniose.

Portanto, esse levantamento de literatura promoveu verificar bases teóricas referentes à avaliação fenotípica e molecular da susceptibilidade à fármacos em isolados clínicos de Leishmania ssp. e também observar lacunas que podem despertar novas pesquisas e comprovações científicas que proporcionam a busca por novos fármacos para diversas espécies de leishmanioses no Brasil.

\section{REFERÊNCIAS}

ArAÚJO,Thalita Fernanda (2019). Estudos fenotípicos de isolados clínicos de Leishmania Infantum. [s.1.] Dissertação (Mestrado em Biologia Animal) - Instituto de Biologia, Universidade Estadual Campinas.

BADIRZADEH, Alireza. et al. Antileishmanial activity of urtica dioica extract against zoonotic cutaneous leishmaniasis. PLoS Neglected Tropical Diseases, Califórnia, EUA, v. I4, n. I, p. I-20, 2020.

BARROS, Daniele Costa Souza. Síntese e avaliação da atividade leishmanicida de novos compostos 4-aminoquinolínicos (2019). Dissertação (Mestrado em Ciências Farmacêuticas) - Escola de Enfermagem e Fármacia, Universidade Federal de Alagoas. Maceió.

BRASIL. Secretaria de Vigilância em Saúde | Ministério da Saúde: Boletim Epidemiológico. Doenças tropicais negligenciadas, versão eletrônica, p. I-76, março 202I. Disponível em: https://www.gov.br/saude/pt$\mathrm{br} / \mathrm{media} / \mathrm{pdf} / 202 \mathrm{I} / \mathrm{marco} / 3 /$ boletim_especial_doencas_negligenciadas.pdf. Acesso em: 07 jul. 2021. 
CONRADO, Gabrielly Galdino (2019). Prospecção e identificação de compostos isolados de phyllanthus amarus Schum and Thon com potencial atividade leishmanicida. [s.1.] Tese (Doutorado em Ciências) - Universidade Estadual de Campinas, Instituto de Biologia, Campinas, SP.

DOS SANTOS NOGUEIRA, Fabio. et al. Use of miltefosine to treat canine visceral leishmaniasis caused by Leishmania infantum in Brazil. Parasites and Vectors. University of Medical Sciences, Kerman, Iran, v. I2, n. I, p. I-II, 2019.

ILAGHI, Mozhde. et al. The potential role and apoptotic profile of three medicinal plant extracts on Leishmania tropica by MTT assay, macrophage model and flow cytometry analysis. Parasite Epidemiology and Control, Kerman University of Medical Sciences, Kerman, Iran , v. 12, 2021.

KATINAS, Jade. et al. Sulfonamides as Inhibitors of Leishmania - Potential New Treatments for Leishmaniasis. Anti-Infective Agents. Chemistry Department, Illinois State University, Normal, IL, USA, v. 15, n. I, p. 57-62, 2017.

LIMA, Viviane Silva. Estudo in vitro da atividade Anti-Leishmania de compostos sintéticos derivados espiro-acridínicos sobre Leishmania Amazonensis. João Pessoa- PB: Departamento de Ciências Farmacêuticas, 2020. [s.l: s.n]. Trabalho de Conclusão de Curso.

MENDES, Andreia Patrícia Moreira (2019). Avaliação in vitro da atividade Anti-Leishmania de compostos sintéticos. [s.l.] Dissertação (Mestrado em Ciências Biomédicas) - Instituto de Higiene e Medicina Tropical, Universidade Nova de Lisboa.

MUENDO, Charity Mutile (2020). Safety Efficacy of prosopis julifora leaf extract as a potential treatment against visceral leishmaniasis. [s.l.] Tese (Master of Science Applied Parasitology) - Kenyatta University.

PAES, Taiana Ferreira (2017). Análise comparativa de aspectos biológicos e moleculares de isolados de Leishmania infantum. [s.1.] Dissertação (Mestrado em Biologia Celular e Molecular) - Instituto Oswaldo Cruz, Rio de Janeiro. 